\title{
A Metabolic Syndrome Case Presenting with Lymphocytic Mastitis
}

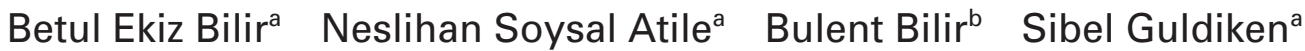 \\ Nermin Tuncbilek $^{c}$ Fulya Oz Puyan ${ }^{d}$ Atakan Sezer ${ }^{\mathrm{e}}$ Irfan Coskun ${ }^{\mathrm{e}}$ \\ aDepartment of Endocrinology and Metabolism, Medical Faculty, Trakya University, \\ bInternal Medicine Clinics, Edirne Public Hospital, Saricapasa, \\ 'Department of Radiology, \\ ${ }^{\mathrm{d} D e p a r t m e n t}$ of Pathology, \\ ${ }^{\text {eDepartment }}$ of General Surgery, Medical Faculty, Trakya University, Edirne, Turkey
}

\section{Keywords}

Lymphocytic mastitis - Metabolic syndrome

\section{Summary}

Background: Lymphocytic mastitis is a disease of premenopausal women, and its association with type 1 diabetes mellitus is the basis for its alternative name 'diabetic mastopathy'. It is a benign condition but must be considered in the differential diagnosis of breast cancer, especially in diabetic patients. Case Report: We present the case of an overweight 50-year-old dyslipidemic woman with metabolic syndrome presenting with lymphocytic mastitis. Conclusion: Although lymphocytic mastitis is usually regarded as an autoimmune disease seen mostly in diabetic patients, it may also be seen in nondiabetic patients with metabolic syndrome who do not have an autoimmune disease.

\section{Introduction}

Metabolic syndrome is a state of metabolic dysregulation characterized by insulin resistance (IR), hyperinsulinemia and a predisposition to type 2 diabetes mellitus (DM). One of the target organs in DM is the breast. Diabetic mastopathy (also termed lymphocytic mastitis), calcifications of breast arteries and breast cancer are some of the conditions associated with DM. Diabetic mastopathy was first described by Soler and Khardori in 1984 as a dense fibrous stromal proliferation that occurred in women with long-standing type 1

\author{
Schlüsselwörter \\ Lymphozytische Mastitis - Metabolisches Syndrom
}

\section{Zusammenfassung}

Hintergrund: Die lymphozytische Mastitis ist eine Erkrankung von Frauen vor den Wechseljahren und die Verbindung mit Typ-1-Diabetes mellitus ist der Grund für die alternative Bezeichnung "Diabetische Mastopathie». Obwohl es sich um eine gutartige Erkrankung handelt, sollte sie, besonders bei zuckerkranken Patientinnen, in der Differenzialdiagnose des Brustkrebses berücksichtigt werden. Fallbericht: Wir berichten über eine 50-jährige übergewichtige dyslipidämische Frau mit metabolischem Syndrom, die mit lymphozytischer Mastitis in unserer Klinik vorstellig wurde. Schlussfolgerungen: Lymphozytische Mastitis ist eine Erkrankung, die normalerweise als eine Autoimmunkrankheit angesehen wird und zumeist bei zuckerkranken Patienten vorkommt. Sie tritt jedoch auch bei nicht diabetischen Patienten mit metabolischem Syndrom auf, bei denen keine Autoimmunerkrankung vorliegt.

DM and multiple microvascular complications [1]. Lymphocytic mastitis is a condition associated with autoimmune diseases such as type 1 DM, Sjögren's syndrome, Hashimoto's thyroiditis and rheumatoid arthritis. It is mostly accompanied by type $1 \mathrm{DM}$, but may sometimes occur in the absence of DM. The pathogenesis of this disease is hypothesized to be an autoimmune reaction to the accumulation of hyperglycemiainduced abnormal matrix. It accounts for less than $1 \%$ of benign breast lesions. To our knowledge, no prior report of lymphocytic mastitis associated with metabolic syndrome has been published.

\section{KARGER \\ Fax +497614520714 \\ Information@Karger.de}

www.karger.com (c) 2012 S. Karger GmbH, Freiburg

$1661-3791 / 12 / 0076-0493 \$ 38.00 / 0$

Accessible online at:

www.karger.com/brc 


\section{Case Report}

A 50-year-old premenopausal woman with painless bilateral breast masses was admitted to our hospital. The patient had no history of DM or hypertension. The medical history of the patient was normal except for intermittent use of statins for dyslipidemia and she was on atorvastatin (10 mg daily) therapy. Her mother and 1 of her sisters had type 2 DM.

An ultrasonographic examination of her breasts revealed multiple cysts with a maximal diameter of $10 \mathrm{~mm}$ and a $4 \times 13 \mathrm{~mm}$ heterogeneous hypoechogenic mass lesion at the left subareolar region, which was vascularized in a patchy manner. The lesion was an ACR-BIRADS (American College of Radiology Breast Imaging-Reporting and Data System) category 4 lesion, so an ultrasound-guided core needle biopsy of the lesion was performed. Histological findings revealed histiocytic proliferation, lymphocytic mastitis signs with giant-cell reaction, lobular atrophy and periductal dense lymphocytic inflammation with fibrosis; there was no evidence of malignancy. These findings were compatible with lymphocytic mastitis (fig. 1). The immunohistochemical examination showed dense CD68 positivity on histiocytes, and prominent CD3 staining on the lymphocytic population. Because of the characteristic association of lymphocytic mastitis to DM, the patient was referred to our endocrinology department outpatient clinic.

Physical examination of the patient revealed a body mass index (BMI) of $28.2 \mathrm{~kg} / \mathrm{m}^{2}$ (weight: $76.9 \mathrm{~kg}$, height: $165 \mathrm{~cm}$ ) and abdominal circumference was higher than accepted upper normal limit (waist circumference: $111 \mathrm{~cm}$, hip circumference: $108 \mathrm{~cm}$, waist-to-hip ratio: 1.02$)$. The arterial blood pressure was $120 / 80 \mathrm{mmHg}$, heart rate was $84 \mathrm{bpm}$ and rhythmic. Other system examinations showed no abnormality. Painless soft hepatomegaly with blunt margins was palpable $4 \mathrm{~cm}$ at the midclavicular line and $2 \mathrm{~cm}$ at subxiphoid region, but there was no splenomegaly. The breast examination revealed multiple painless, soft, mobile lumps with indefinite margins. No lymphadenopathy was detected anywhere over the body including the axillary region.

Laboratory examination of fasting plasma revealed: $107 \mathrm{mg} / \mathrm{dl}$ glucose, $12.7 \mu \mathrm{U} / \mathrm{ml}$ insulin, $3.4 \mathrm{ng} / \mathrm{ml} \mathrm{C}$-peptide, 6.1\% hemoglobin A1c, $170 \mathrm{mg} / \mathrm{dl}$ triglyceride, $209 \mathrm{mg} / \mathrm{dl}$ total cholesterol, $45 \mathrm{mg} / \mathrm{dl}$ HDL-cholesterol, $160 \mathrm{mg} / \mathrm{dl} \mathrm{LDL}$-cholesterol, and $0.9 \mathrm{mIU} / \mathrm{ml} \mathrm{TSH}$; the plasma was negative for anti-thyroglobulin and anti-thyroid peroxidase antibodies. Because assays for anti-nuclear antibody (ANA) and rheumatoid factor were negative and there were no other clinical findings, rheumatological disorders were ruled out. Renal and hepatic function tests were within normal limits. A low-dose dexamethasone suppression test ruled out Cushing's syndrome. The venous blood glucose level was $180 \mathrm{mg} / \mathrm{dl}$ after a 2-h oral glucose tolerance test with 75 g glucose. The patient's diagnosis was impaired fasting glucose (IFG) and impaired glucose tolerance (IGT) according to the revised 2003 diagnostic criteria of the Expert Committee of the American Diabetes Association. The level of the homeostasis model assessment ratio (HOMA-R, a marker of IR) of the patient was 3.36, i.e. higher than normal (HOMA-R is obtained as: fasting insulin $(\mu \mathrm{U} / \mathrm{ml}) \times$ fasting plasma glucose $(\mathrm{mg} / \mathrm{dl}) / 405)$.

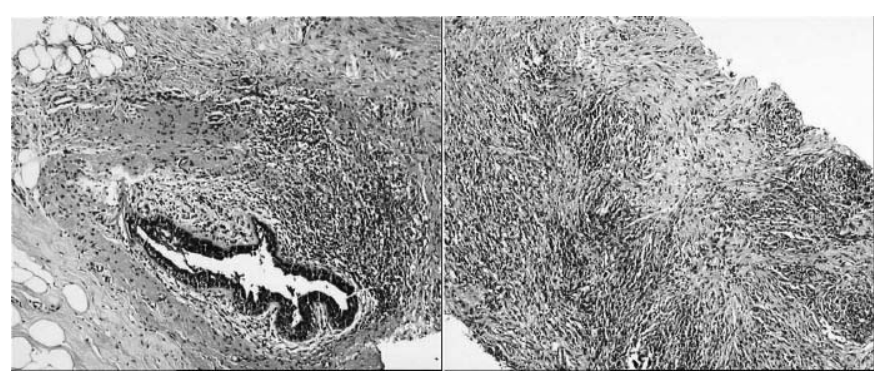

Fig. 1. Left: Periductal dense lymphocytic inflammation surrounds the ducts. Right: Histiocytes, lymphocytes and plump fibroblasts are seen in the inflammatory collagenous stroma (hematoxylin and eosin, $\times 50$ ).
In summary, the clinical data of the patient showed: higher than normal waist circumference $(>80 \mathrm{~cm})$, fasting plasma glucose $(>100 \mathrm{mg} / \mathrm{dl})$ and triglyceride levels (> $150 \mathrm{mg} / \mathrm{dl})$; a lower-than-accepted HDL lower limit ( $<50 \mathrm{mg} / \mathrm{dl}$ for women); and the presence of IR and IGT. According to the following different sets of criteria, the patient's values fulfilled, and were sufficient for, a diagnosis of the metabolic syndrome [2]: Adult Treatment Panel III (2001) criteria (3 variables: high abdominal circumference, high triglyceride levels and low HDL value); WHO (1998) criteria (IGT and 2 other criteria: here increased triglyceride levels and high waist to hip ratio in women); International Diabetes Federation (2005) criteria (increased abdominal circumference and 2 other criteria: here increased triglyceride levels and low HDL value).

\section{Discussion}

Lymphocytic mastitis is a new clinical entity about which increasingly more information and case reports are being published. Clinical presentation of the disease is usually suspicious fibrous breast lumps, which are commonly multiple, bilateral, and recurrent. On physical examination, lesions are mobile, non-tender, firm, coarse, and frequently flat.

The typical mammographic appearance of this condition is increased asymmetric, ill-defined, regional parenchymal density and/or localized stromal distortion, but no focal mass. Ultrasonographic examination typically shows the appearance of an ill-defined heterogeneously hypo-echoic mass with strong distal acoustic shadowing and an absence of Doppler signal. Magnetic resonance imaging can be helpful in differentiating this lesion from malignancy. Nevertheless, a core biopsy or excisional biopsy should be performed to make the definitive pathological diagnosis. If the pathological findings are suspicious on core biopsy, as a the next step, an excisional biopsy must be done to rule out neoplasia.

On the pathological gross examination, the masses are firm with homogeneous tannish-white cut surfaces. Pathological findings are lymphocytic lobulitis and ductitis with focal glandular atrophy, lymphocytic/mononuclear perivascular inflammation and dense often keloid-like fibrosis with or without peculiar epithelioid cells embedded in dense fibrous stroma (provisionally labeled as 'epithelioid fibroblasts'). Although the features of lymphocytic lobulitis, ductitis, and/ or vasculitis may occasionally be encountered in non-diabetic breast biopsies, according to Tomaszewski et al. [3], epithelioid fibroblasts appear to be unique to the diabetic condition. In our case, plump fibroblasts with a dense inflammatory background with lymphocytic ductitis and lobulitis were consistent with lymphocytic mastitis. On immunohistochemical staining, dense $\mathrm{CD}^{+}$and scattered $\mathrm{CD} 20^{+}$cells were detected, indicating the $\mathrm{T}$ lymphocyte predominance. Lymphocytic infiltration in diabetic mastopathy consists predominantly of B lymphocytes, similar to other autoimmune diseases, while in non-diabetic mastitis this consists mainly of $\mathrm{T}$ lymphocytes. The T lymphocyte predominance may be due to the absence of a diabetic or autoimmune background in our case. 
The disorder documented by these pathological changes, with or without DM, has been termed diabetic mastopathy, sclerosing lymphocytic lobulitis of the breast, fibrous mastopathy or lymphocytic mastopathy $[4,5]$. Diabetic mastopathy is an unusual mostly immune-mediated fibroinflammatory breast lesion that characteristically presents in premenopausal women with long-standing type $1 \mathrm{DM}$ with multiple microvascular complications. The pathogenesis of this condition is believed to involve a secondary autoimmune reaction to abnormal extracellular matrix accumulation that is a manifestation of the effects of hyperglycemia on connective tissue. Hyperglycemia per se, by inducing glycosylation, increased intermolecular cross-linkage, and degradation resistant matrix expansion, results in a 'neoantigen' development triggering a secondary autoimmune reaction, with B cell proliferation and autoantibody formation [5]. Advanced glycosylation end products (AGEs) are removed by macrophages, which secrete cytokines to the milieu that behave as growth factors and induce additional matrix expansion and proliferation of collagen [3].

Lymphocytic mastitis can simulate a malignant neoplasm on physical examination. However, unlike some other autoimmune diseases, it is not associated with either an increased incidence of epithelial or stromal neoplasia or a premalignant lesion for lymphoma [6]. Some cases of lymphocytic mastitis are associated with autoimmune diseases other than type 1 DM, such as Hashimoto's thyroiditis, systemic lupus erythematosus and Sjögren's syndrome [7, 8]. However, there are also some patients with lymphocytic mastitis who have no associated autoimmune disease or have only type $2 \mathrm{DM}$, which is not an autoimmune disease [9].

To our knowledge, this is the first reported case of lymphocytic mastitis presenting only with metabolic syndrome without DM. Most cases with lymphocytic mastitis in the literature had type 1 diabetics with microvascular complications, but our patient had neither type 1 nor type $2 \mathrm{DM}$. She was a pre- diabetic woman with metabolic syndrome. In a review article by Ely et al. [9], 19 cases with diabetic mastopathy were presented, and 3 (29, 32 and 51 years old) were neither diabetic nor had any autoimmune diseases, like our case.

The high A1c value identifies our patient as an individual with high risk for future DM. Because prediabetes is a preliminary state to the overt DM, it may be possible that lymphocytic mastitis may occasionally precede the onset of clinically overt DM. According to a report of the Diabetes Prevention Program Research Group, retinopathy, which is the hyperglycemic complication most closely associated with DM, may occur over a wider continuum of glycemia, especially during the IGT period [10]. Therefore, if hyperglycemia at the prediabetic levels can cause such a complication at the retinal tissue, it may also cause complications in the breast tissue. As postulated previously by Tomaszewski et al. [3], the hyperglycemic state at the level of the breast tissue may cause the formation of AGEs, inducing the release of some cytokines and triggering an inflammatory response. Moreover, obesity is regarded as a subclinical inflammatory condition that promotes the production of pro-inflammatory factors involved in the pathogenesis of IR [11]. In particular, abdominal obesity and its related adipokines have been blamed for this systemic inflammatory reaction. It may be that the adipokines released from the increased adipose tissue of the patient caused the inflammatory reaction in the breast tissue, which also has a high fat content.

In conclusion, diabetic mastopathy may be encountered in patients with metabolic syndrome without diabetes or who do not have an autoimmune disease.

\section{Disclosure Statement}

We certify that this work received no funding or sponsorship that could lead to possible conflict of interest.

\section{References}

1 Soler NG, Khardori R: Fibrous disease of the breast, thyroiditis, and cheiroarthropathy in type I diabetes mellitus. Lancet 1984;1:193-195.

- 2 Grundy SM, Cleeman JI, Daniels SR, Donato KA, Eckel RH, Franklin BA, Gordon DJ, Krauss RM, Savage PJ, Smith SC Jr, Spertus JA, Costa F: Diagnosis and management of the metabolic syndrome: An American Heart Association/National Heart, Lung, and Blood Institute scientific statement. Circulation 2005;112:2735-2752.

>3 Tomaszewski JE, Brooks JS, Hicks D, Livolsi VA: Diabetic mastopathy: A distinctive clinicopathologic entity. Hum Pathol 1992;23:780-786.
4 Garstin WJH, Kaufman Z, Michell MJ, Baum M: Fibrous mastopathy in insulin-dependent diabetics. Clin Radiol 1991;44:89-91.

5 Schwartz IS, Strauchen JA: Lymphocytic mastopathy: An autoimmune disease of the breast. Am J Clin Pathol 1990;93:725-730.

6 Valdez R, Thorson J, Finn W, Schnitzer B, Kleer CG: Lymphocytic mastitis and diabetic mastopathy: A molecular, immunophenotypic, and clinicopathologic evaluation of 11 cases. Mod Pathol 2003;16:223-228.

7 Ashton MA, Lefkowitz M, Tavassoli FA: Epithelioid stromal cells in lymphocytic mastitis--a source of confusion with invasive carcinoma. Mod Pathol 1994;7:49-54.
8 Ríos G, Peredo RA: Lymphocytic mastitis preceding Sjögren's syndrome. P R Health Sci J 2010; 29:127-129.

9 Ely KA, Tse G, Simpson JF, Clarfeld R, Page DL: Diabetic mastopathy: A clinicopathologic review. Am J Clin Pathol 2000;113:541-545.

10 Diabetes Prevention Program Research Group: The prevalence of retinopathy in impaired glucose tolerance and recent-onset diabetes in the Diabetes Prevention Program. Diabet Med 2007;24:137-144.

11 Bastard JP, Maachi M, Lagathu C, Kim MJ, Caron M, Vidal H, Capeau J, Feve B: Recent advances in the relationship between obesity, inflammation, and insulin resistance. Eur Cytokine Netw 2006; 17:4-12. 